\title{
Rational Organizational and Technological Solutions for Plastering
}

\author{
Boris Vasilyevich Zhadanovsky ${ }^{\mathrm{a}}$, Vladimir Evgenievich Bazanov ${ }^{\mathrm{b}}$ \\ ${ }^{a}$ Candidate of Technical Sciences, Professor, Moscow State University of Civil Engineering, 26 Yaroslavskoye Shosse, Moscow, \\ 129337, Russia. \\ ${ }^{b}$ Candidate of Technical Sciences, Associate Professor, Moscow State University of Civil Engineering, 26 Yaroslavskoye Shosse,
} Moscow, 129337, Russia.

Received 12 December 2019; Accepted 13 April 2020

\begin{abstract}
Stucco jobs make a considerable share in the total scope of finishing construction operations. Stucco jobs represent an intricate technology involving a great number of manual operations. Mechanization of stucco operations allows reducing labor costs on their performance and increasing labor productivity. This paper is aimed at the selection of optimal workplace practices during façade stucco jobs using powered tools to treat concrete and brick surfaces of outer walls of buildings and facilities. The paper discusses organizational and technological solutions in performing façade stucco jobs including workplace management, workflow process, and equipment and tools utilized. An overview of existent powered tools for the treatment of concrete and brick surfaces is given; the results of undertaken testing of milling tools for the treatment of concrete and reinforced concrete structures are analyzed. Based on the study findings, the authors have concluded that in the improvement of productivity and quality of façade finishing jobs, a great role belongs to correct (rational) organization of labor using the straightforward segmented workflow, performance of works by specialized crews of workers, and utilization of high-performance tools and appliances. Different locations and composition of surfaces being stuccoed require different types of powered tools. The development of new prototypes and the improvement of existent powered tools for surface treatment allows increasing efficiency and reducing the cost of work. New options of star inertia mills made of different materials for powered tools equipped with a flexible roll are suggested.
\end{abstract}

Keywords: Plastering; Technological Solutions; Mechanized Concrete Processing; Milling Cutters; Inertial Mills; Carbide Tools.

\section{Introduction}

Finishing work in construction is a laborious and responsible process. They ensure the durability of buildings and their elements, protecting structures from atmospheric influences, and improve the artistic perception of structures. Plastering is one of the types of decoration of buildings and structures. Plastering works are widely used both in new construction and in restoration work to preserve historical and architectural monuments. Plastering is a complex technology, which uses a large number of manual operations [1, 2]. Despite the development of mechanization, their volume remains significant and in some cases reaches $60 \%$.

To increase labor productivity, a rational, economically sound organization of labor, the acquisition of brigades and units by skilled workers, and the use of high-performance equipment, tools, and devices are necessary. These issues are periodically reviewed and investigated by various authors.

\footnotetext{
* Corresponding author: bazanov_kim@mail.ru 
Different techniques of stucco jobs (both manual and mechanical) have their own advantages, areas of efficient use, and promising directions for development [3-5]. Stucco job mechanization allows reducing labor costs and improving performance. Stucco job automation realized through use of stucco robots and the findings of a mathematic model of automatic stucco job management system are presented in the studies by Bock et al. (2018) [6]. The results of creation and application of an automated wall stuccoing system are discussed in Shreeranga et al. (2017) [7] and Ankush and Laukik (2017) [8] studies. The proposed machines include an AC electric motor, gear box, cord mechanism, pulley, batch tray, and guide paths. The machine model was made with regard to a high-quality brick wall and then checked by on-line testing.

The quality of façade stucco, the cost and completion dates of jobs depend on the structural and technological solutions chosen [9], the choice of materials and appropriate equipment for leveling finishing coatings [10, 11].

The influence of various factors on the performance of stuccoworkers teams is investigated using both statistical and mathematic modeling methods. It was established based on a large number of statistical data [12, 13] that process efficiency largely depends on the surface type and location, operational procedures and workplace management, qualifications of team members, and experience of workers. The study utilized the methods of DEA (Data Envelopment Analysis), regression and correlation analysis, wherein a significant variance in labor productivity at similar projects was noted. Application of construction process modeling for more precise evaluation of labor productivity is discussed by Bokor et al. (2019) [14] and Lapidus et al. (2018) [15].

Good quality of outer wall preparation - leveling and buffing with powered tools - is very important in stucco job performance. For mechanical treatment of reinforced concrete, concrete and stone surfaces, high-performance machines equipped with diamond and carbide-tipped tools are used [16]. Appearance of new materials and development of new tools necessitate improving the methods of building structures treatment with abrasive materials and undertaking studies on structures treatment and principles of calculating parameters of buffing using loose abrasives [17].

Since January 2020, GOST R 57984-2017 has been implemented in the Russian Federation, identical to the European standard EN 13914-1: 2005 "Design, preparation and application of external rendering and internal plastering - Part 1: External rendering". These standards reflect the main technological rules for the preparation and execution of plastering works. However, organizational issues of work are not considered. Meanwhile, the organization of work remains one of the important aspects of improving their quality and productivity [18].

This article considers rational organizational and technological solutions for the production of works, including the organization of the workplace, the sequence of work, the equipment and tools used (traditional and modern). An overview of existent special equipment and tools for mechanical treatment of concrete and brick surfaces, such as buffing mills with hard metal stars, has been undertaken. The results of laboratory testing of powered tools for treatment (leveling) of walls made of different materials are given.

\section{Materials and Methods}

Production of stucco jobs was organized using the straightforward segmented work flow which is straightforward performance of works wherein the stucco process is broken down into separate simple operations. The main form of organizing the work of workers in plastering is the implementation of their specialized units of workers, united in specialized teams. The production of works is carried out mainly using the flow-split method of labor organization: continuous production of work with the division of the plastering process into separate simple operations. The dissected organization of the workflow allows to get high technical and economic indicators (increased labor productivity and overall acceleration of work due to the specialization and qualification of performers in performing repeated operations).

The composition of the units and teams of plasterers is formed in each specific case, depending on the nature and total amount of work on the capture. The required number of workers is determined by the size of the front of work, which can be provided by the applied means of mechanization, taking into account the level of implementation of production standards. The qualification of performers must meet the requirements of professional standards for the quality of individual processes.

Characteristics of star inertia mills for surface treatment were studied in the course of laboratory tests. Test stars were made with sharp tips or of combined type (with teeth made of hard alloys). Star diameter varied between 35 and $50 \mathrm{~mm}$. The following materials were chosen to fabricate the stars: according to the Russian classification - steel R18 (analogue of EN 1.3355), steel 40Kh (analogue of EN 37Cr4), steel ShKh-15 (analogue of EN 1.3505), as well as combined reinforced plates from baked hard tungsten-cobalt alloy VK8 (analogue of DIN HG30). The number of mill rounds changed from $600 \mathrm{rpm}$ to $2200 \mathrm{rpm}$. Mills were tested on concrete plate samples sized $25 \times 40 \times 4 \mathrm{~cm}$ with compression strength of 10,15,20, and $30 \mathrm{MPa}$. As a coarse concrete filler, lime, marble, and granite were used. In 
the course of tests, dependence of the relief height of treated concrete surface at different mill rpms and star material wear were studied.

\section{Results and Discussion}

The construction processes that are part of the plastering of facades (for multi-layer plaster systems) are carried out in the following technological sequence:

- Surface preparation;

- Hanging walls and installing beacons;

- Reception of the prepared plaster mortar and its transportation to workplaces;

- Sequential application of the lower (base) layer of the solution (or several layers);

- Application of the upper (decorative-protective) layer of the solution and its grout;

- Plastering slopes and ebbs;

- Pulling rods with cutting angles;

- Care for fresh plaster.

The plastering processes should be distributed between specialized units as follows:

Crew 1 - Preparation of surfaces manually or mechanized;

Crew 2 - The application of the lower layer (s);

Crew 3 - Applying and grouting the upper layer of the solution;

Crew 4 - Plastering slopes and ebbs, pulling rods with cutting angles, cutting rust (if necessary).

The level of qualification of performers in the composition of the crews is determined by the requirements of professional standards for the implementation of the corresponding labor functions (construction operations). Depending on the general direction of performing external plastering, the building facades are divided into vertical (Figure 1a) or horizontal grips (Figure 1b).

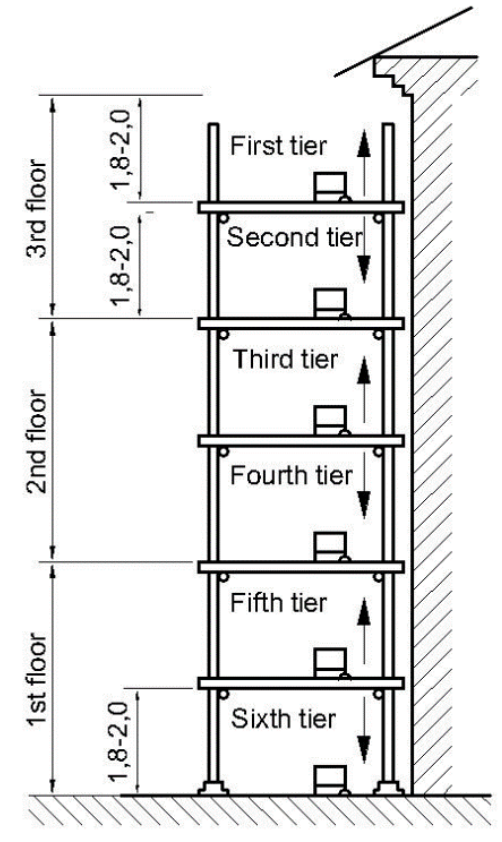

(a)

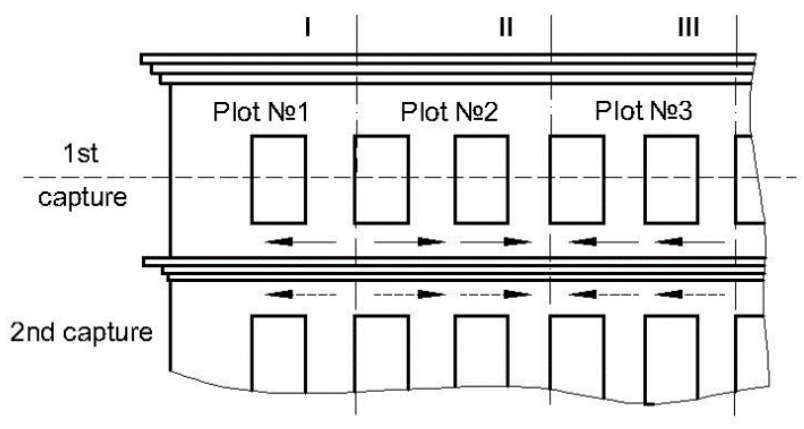

(b)

Figure 1. Organization of work on plastering the facade with a breakdown: (a) for vertical captures; (b) for horizontal captures

When working on vertical grips, the crews are arranged in tiers. The length of the capture on the tier is determined taking into account the daily production of crews. Simultaneous work on different tiers should be carried out with strict observance of safety rules for work. 
When the facade is broken down into horizontal grips, the crews are arranged along the entire front of the work within the grips, and each crew occupies a certain plot. The size of the plots is determined by the daily production of crews. Work on plots is carried out from the borders of adjacent plots in opposite directions.

In general, work is performed in all cases in the direction from top to bottom (from the cornice to the socle of the aerial part of the foundation). The procedure for providing work with plaster solutions is determined for each specific object: a receiving device for processing the finished solution is equipped on an on-site site or a mobile mortar unit (mortar station) for preparing a solution on-site from a dry commercial plaster mixture or from a mixture of individual components. For small amounts of work, it is advisable to use small-scale plaster stations (mortar mixers) to prepare a solution from plaster mixtures or to perform manual mixing with the help of an electric tool. Next, the sequence, methods and techniques of work in plastering the facade were considered.

Crews 1 performs mechanized cleaning of the surface from dust, dirt, salt deposits, felling of flows, sealing of sinks, notching of smooth concrete and stone walls, hanging surfaces. Dust from the surface of the facade is removed by a jet of compressed air from the compressor, flushing is carried out with water.

Cutting down of flows and notching of concrete and stone surfaces on small areas is made manually with the help of chisels and hammers, scarpels. On large areas, mechanized tools are used: pneumatic and electric grinders, electric brushes, sandblasting machines, cleaning cutters [19, 20].

The entire surface and elements of the facade are verified to determine the degree of deviation of the surfaces and faces from the horizontal and vertical. Reconciliation of vertical (side) slopes of window openings located on the same axis is performed by hanging them with a plumb line lowered through all floors from the upper floor window. The cord along the lines of their faces along the facade is stretched to reconcile the location of the upper slopes and drains of window openings (Figure 2).

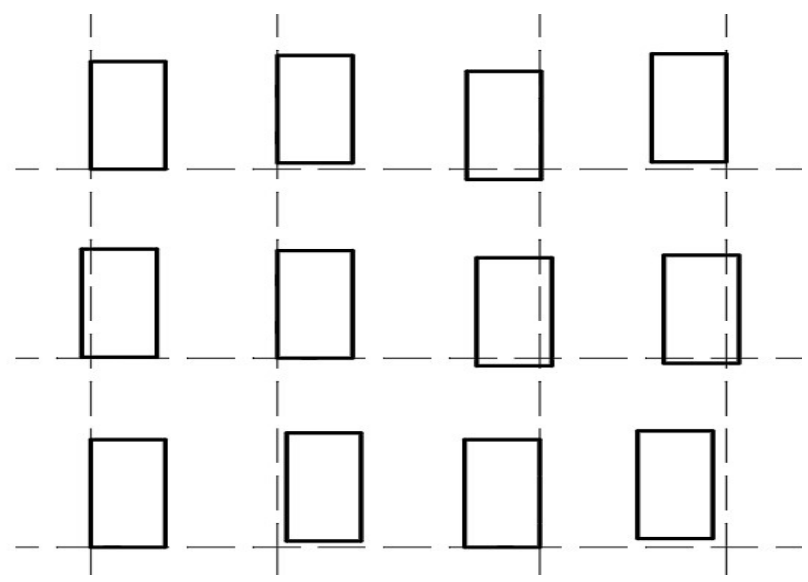

Figure 2. Sagging facade

The places of mismatch of slopes and drains with the corresponding vertical and horizontal lines are corrected by cutting the protruding parts of the bases or by increasing the thickness of the plaster within the permissible limits (GOST R 57984-2017 / EN 13914-1-2005).

If necessary (for example, when plastering the facade for painting), crew 1 also performs the installation of beacons. Lighthouses are installed at all corners of the facade and on the sides of window openings. With a significant width of window openings and piers, additional beacons are installed so that the leveling of the solution between them can be done using working rules with a length of $1.5-2.0 \mathrm{~m}$. The thickness of the beacons should correspond to the thickness of the lower (base) layer of plaster.

Crew 2 applies the base layer of plaster (from one or more layers) sequentially as the underlying layer sets. The solution is applied mechanically or manually.

The surface of the lower layer is well compacted and leveled. If necessary, the surface of the lower layer is cut horizontally with wavy grooves with a depth of at least $3 \mathrm{~mm}$. Cement window sills are performed manually using the appropriate tool, with further installation of metal sinks.

Crew 3 before applying the decorative upper layer produces (if necessary) wetting the lower layer by spraying water. The top coat is applied mechanically.

Crew 4 performs part of the work before the work of crews 2 and 3. The traction of belts, platbands and pilasters is carried out before plastering smooth surfaces. The slopes of the openings are plastered before applying the top layer of plaster. At the same time, the joints of the plaster are made not on the front surface of the wall, but on the edges of the 
slopes. Profiles of cornices, belts, platbands are first stretched in the lower base layer, and after hardening, the upper layer is applied. Templates are used to perform plaster rods.

In the production of external plastering works, the team is equipped with a set of appropriate mechanisms, tools, devices and equipment.

In general, the plasterers team uses the following set of equipment, tools, and devices (in parentheses are references to state standards of the Russian Federation for the respective products):

\section{a) Equipment}

- Plaster Station - for the preparation, processing, transportation and application of the solution during its delivery over a considerable distance;

\section{b) Mechanized tools}

- Electric hammer or pneumatic hammer - for cleaning the surface;

- Milling cutter - for leveling the surface,

- Furrower - for cutting furrows or grooves,

- Trowels - for grouting the top layer;

- Mixer - for manual preparation (kneading) of a plaster mortar;

- Plaster pneumatic hopper bucket (mortar) - for applying mortar to the wall.

\section{c) Hand tools}

- Falcon duralumin - for applying the solution to the surface and leveling it; duralumin Falcon - for applying the solution to the surface and leveling it;

- Rule (wood or aluminum profile rail) (GOST R 58519-2019. Rules, graters and graters. Technical conditions / GOST R 58519-2019. Darbies, floats and semifioats. Specifications) - for leveling the bottom layer;

- Large grater $1.2 \times 0.11 \mathrm{~m}$ - for leveling the solution;

- Wooden half-glass;

- Small grater $0.35 \times 0.05 \mathrm{~m}$ - for cutting corners;

- Wooden grater - for leveling the lower and upper layers;

- Felt grater - for grouting the top layer;

- A steel smoothing iron small and large - for leveling and smoothing the top layer;

- Plaster trowel (GOST 9533-81 Trowels, tuck pointing tools. Specifications) - for spraying the mortar;

- Mortar shovel (GOST 19596-87. Shovels. Specifications) - for shoveling and supplying a solution;

- Plastering construction hammer (GOST 11042-90 Construction steel hammers. Specifications);

- Brush (GOST 10597-87 Painting brushes. Specifications) - for spraying the plaster layer with water during grouting, washing contaminated surfaces, washing tools;

- Metalwork chisel $10 \times 60^{\circ}, 20 \times 60^{\circ}$ (GOST 7211-86. Cold chisels. Specifications) - for cutting down influxes;

- Scarpel - for cutting down influxes;

- Double-edged hammer - for cutting sagging;

- Cutting type OSH-1 (GOST 9533-81 Trowels, tuck pointing tools. Specifications) - for cutting corners;

- Manual steel brushes - for cleaning surfaces;

- Plastering bucket - for applying mortar.

\section{d) Measuring instruments}

- A plumb weighing 400 - 600 g (GOST 7948-80 Steel construction plumb-lines. Specifications) - to check the verticality of structural elements;

- Building level 300 - $700 \mathrm{~mm}$ long (GOST 9416-83 Building levels. Specifications) - to check the horizontal structure;

- Standard cone (GOST 5802 - 86 Mortars. Test methods) - to check the mobility of the solution; 
- Plumb rail (GOST 5802-86 System of ensuring geometric parameters accuracy in building. Rules for measuring parameters of buildings and works) - for quality control of plaster;

- Wooden square - for cutting corners;

- A metal square with a mobile bar - for marking slopes;

- Measuring metal tape measure up to $20 \mathrm{~m}$ long (GOST 7502-98 measuring metal tapes. Specifications) - for measurements.

\section{e) Devices}

- Plaster nozzles - for applying solutions;

- Plaster corners - metal products for the formation of external corners;

- Building mesh (GOST 3826-82. Wire cloth nets with square mesh. Specifications) - mounted between beacons when a thick layer of mixture is applied on an uneven surface;

- Paint net - the material is laid on the wall with shallow cracks when applying a thin layer of plaster.

\section{f) Production inventory}

- Plaster box - for storing solutions in the workplace;

- Buckets - for storing water;

- Rubber hoses and hoses with a length of 15 - $20 \mathrm{~m}$ - for transporting solutions.

The use of special equipment makes it easier to carry out work, shorten the time for their completion and ensure a high-quality result. Before finishing layers, including stucco, are applied onto concrete and reinforced concrete structures, their surfaces must be stripped of fins and other defects which it is expedient to do with powered tools. An effective way of leveling concrete and cleaning surfaces is the use of milling cutters (for example, the production of Metabo, Festool). As the working body, milling heads (Figure 3) are used, equipped with solid metal milling sprockets. Asterisks can be produced in various types: with a pointed tooth (for removing hard plaster, concrete) and with a flat tooth (for removing soft plaster, fresh concrete).
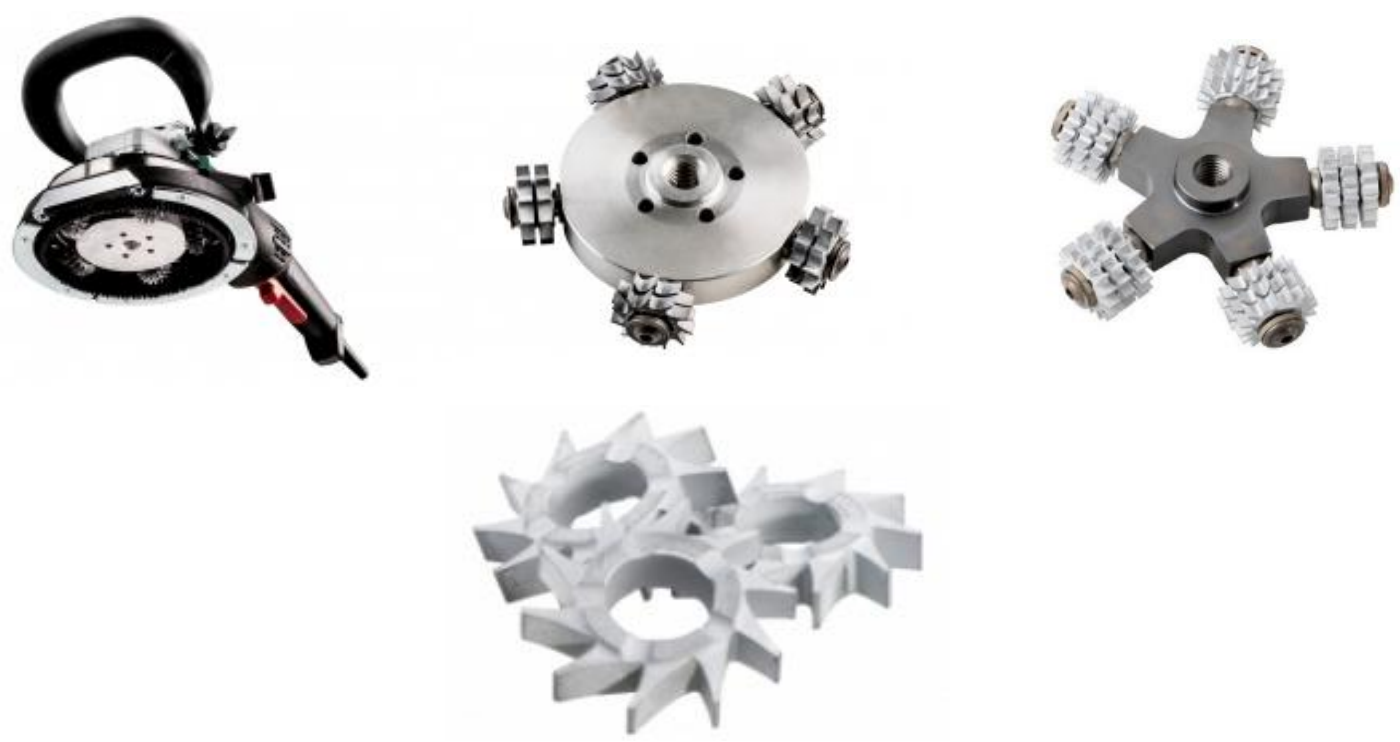

(a)
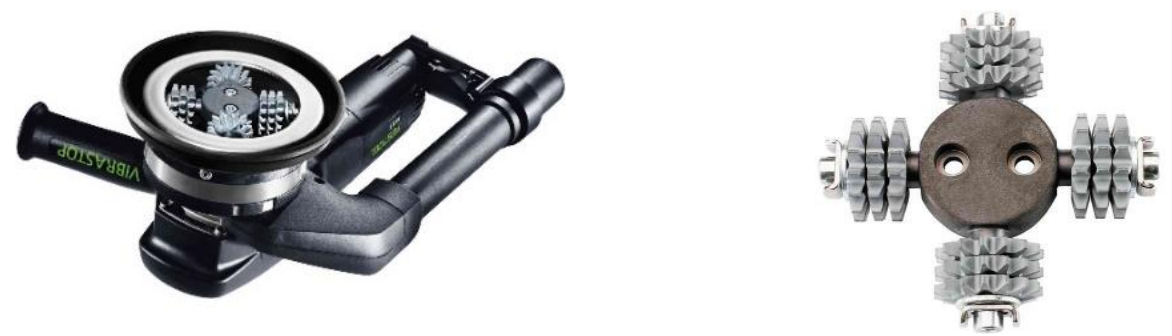

(b)

Figure 3. Milling cutter for leveling concrete: (a) manufactured by Metabo (www.metabo.com); (b) production of Festool (www.ftool.ru) 
For textured finishing of vertical (facades) and horizontal elements of buildings and structures, in addition to the considered milling cutters with inertial carbide sprockets, shank cutters or groove cutters can be used (Figure 4). They allow to make notches or cut grooves with a variable width $(3-40 \mathrm{~mm})$ and a cutting depth $(10-40 \mathrm{~mm})$.
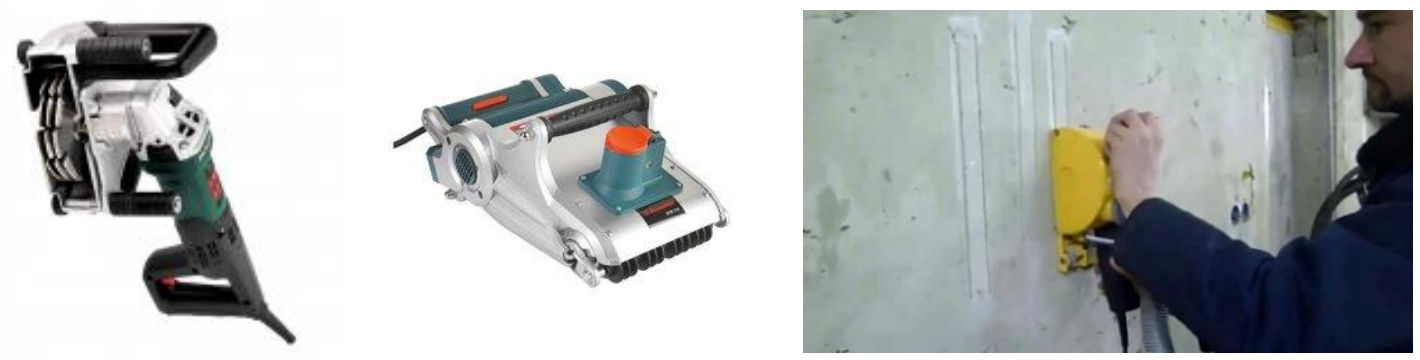

Figure 4. Wall chaser (sidex.ru)

Along with the considered equipment for removing sagging and uneven walls, it seems rational to use mechanized tools with a flexible shaft. As a drive, electric grinders with a flexible shaft can be used (such as IE-8201A machines previously manufactured in Russia - Figure 5) or an inertial vibrator drive for compacting concrete.

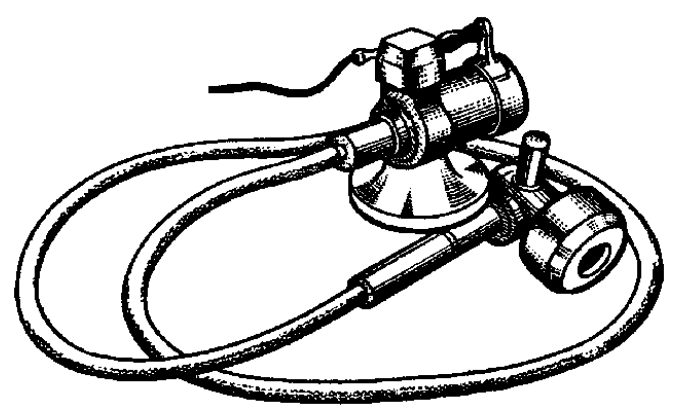

Figure 5. Electric Hand Grinders with Flexible Shaft

As a working element, sprocket-shaped inertial mills are used. Asterisks can be spiky (Figure 6a) and combined with carbide teeth (Figure 6b).
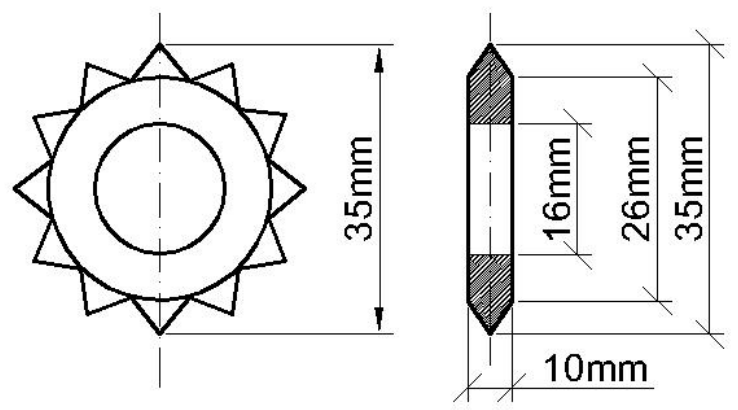

(a)
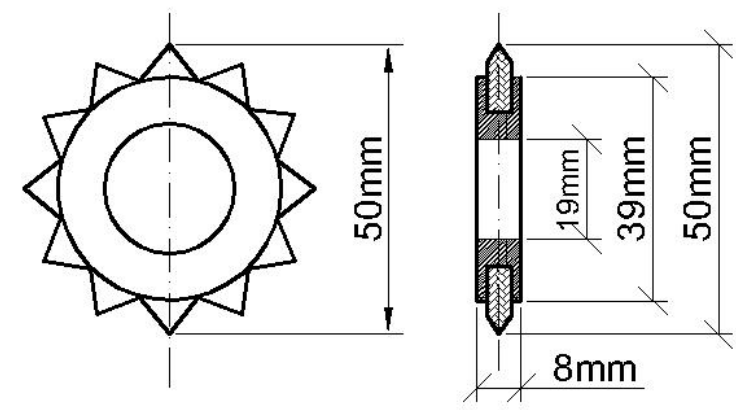

(b)

Figure 6. Schemes of inertial mills: (a) Spiky; (b) Carbide teeth

The location of the sprockets on the shafts of the centrifugal mill can be ordinary or staggered (Figure 7).

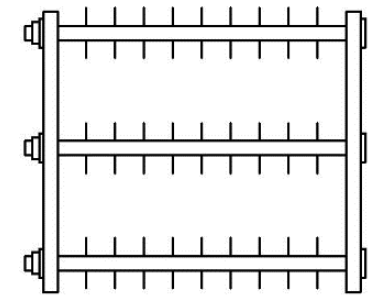

(a)

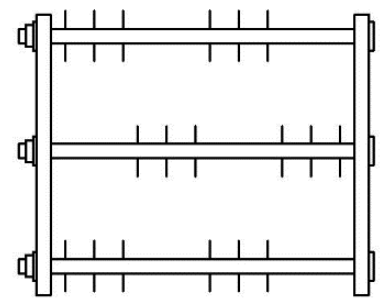

(b)

Figure 7. The arrangement of the sprockets on the shaft of the centrifugal mill: (a) Ordinary location; (b) Chess

To evaluate tool productivity and efficiency in outer wall treatment, laboratory tests of mills made of different materials were carried out: according to the Russian classification, steel R18 (analogue of EN 1.3355), steel 40Kh 
(analogue of EN 37Cr4), steel ShKh-15 (analogue EN 1.3505), as well as combined reinforced plates from sintered hard tungsten-cobalt alloy VK8 (analogue to DIN HG30). The minimum milling performance was shown at a frequency of $600 \mathrm{rpm}$. With increasing speed, productivity increased (Figure 8).

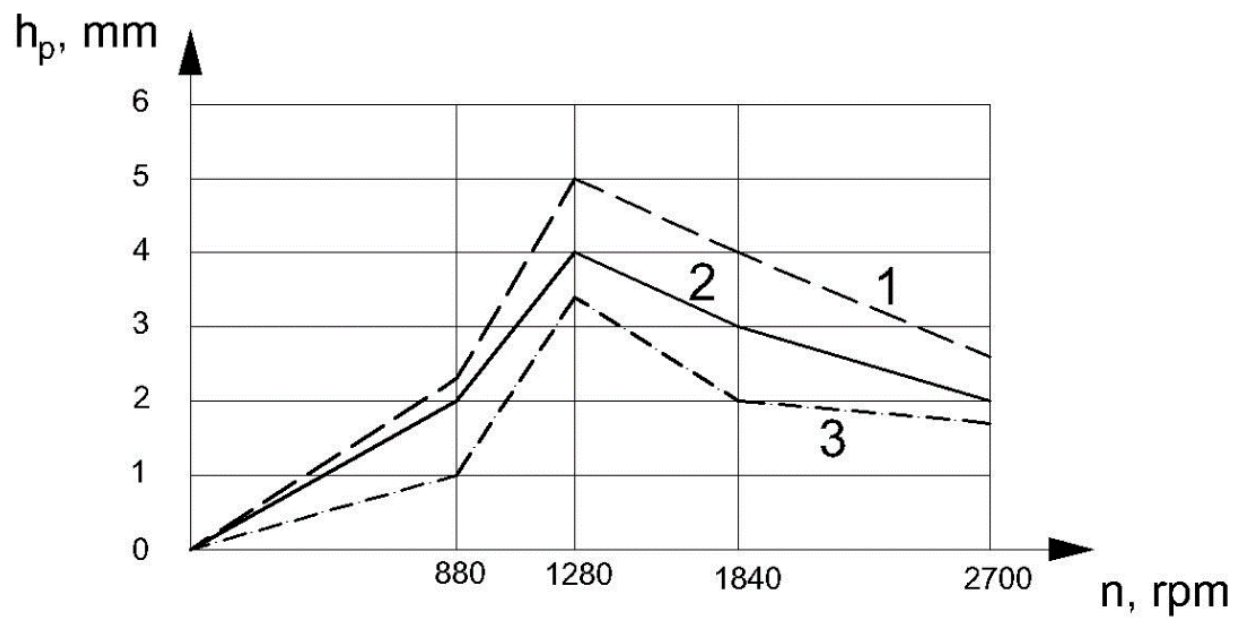

Figure 8. The dependence of the height of the relief $h_{p}$ the machined concrete surface on the peripheral speed $n$ of the rotation of the cutter: (1) concrete with marble aggregate $15 \mathrm{MPa}$; (2) concrete with limestone aggregate 20 MPa; (3) concrete with granite aggregate $30 \mathrm{MPa}$.

The best results were obtained with a sprocket diameter of $45 \mathrm{~mm}$ and a tooth pitch of $11 \mathrm{~mm}$ (13 teeth around the circumference). It was also found that when the distance between the acute-angled sprockets is $8 \mathrm{~mm}$, the chips from their impacts converge, which reduces the surface roughness.

The mills were tested on concrete tiles-samples of size $25 \times 440 \mathrm{~cm}$ with compressive strength of $10,15,20$ and $30 \mathrm{MPa}$. The best effect was manifested for medium and high strength concrete: 15-20 MPa (Aggregate - Marble and Limestone) and 30 - $35 \mathrm{MPa}$ (Aggregate - Granite). Concretes of low strength (10 - $15 \mathrm{MPa})$ are processed less efficiently due to punctures of coarse aggregate, the formation of shells and the collapse of the edges of the grooves. At the same time, sprocket wear was assessed as a percentage by weight. The wear of the sprockets from various types of steel was: R18 steel $-0.16 \%$, steel $40 \mathrm{Kh}-0.16 \%$, steel ShKh-15- $0.17 \%$, VK8 plates $-0.01 \%$.

Treatability of concrete and reinforced concrete depends mostly on abrasive and strength characteristics of its components - fine and coarse filler that might make up to $80 \%$ of the total volume of concrete. Therefore, the choice of mechanical treatment parameters depends on treatability of rock used for production of concrete fillers. Based on the test results, preliminary conclusions were made concerning applicability of inertial tool stars for treatment of concrete featuring different physical and mechanical properties of fillers (Table 1).

Table 1. Characterization of inertia tool materials for matured concrete treatment

\begin{tabular}{lc}
\multicolumn{1}{c}{ Type of Concrete and Reinforced Concrete } & Recommended Steel Grade \\
\hline $\begin{array}{l}\text { Heavy concrete based on silicate rock fillers with compression strength of the input } \\
\text { rock of } 250 \text { to } 450 \mathrm{MPa} \text { (Granites, Basalts, Sandstones) }\end{array}$ & $\mathrm{VK} 8,40 \mathrm{Kh}$ \\
$\begin{array}{l}\text { Heavy concrete based on carbonate rock fillers with compression strength of input } \\
\text { rock of } 150 \text { to } 250 \mathrm{MPa} \text { (Tight Limestones) }\end{array}$ & $\mathrm{R} 18,40 \mathrm{Kh}$ \\
$\begin{array}{l}\text { Heavy concrete based on carbonate rock fillers with compression strength of input } \\
\text { rock up to } 150 \mathrm{MPa} \text { (Marbles) }\end{array}$ & $40 \mathrm{Kh}, \mathrm{ShKh}-15$ \\
\hline
\end{tabular}

\section{Conclusion}

Taking into account the importance and complexity of façade finishing jobs in the total scope of construction operation, selection of the best labor practices for their performance is a highly relevant matter. The straightforward segmented work flow is widely used in construction. The practical benefit of splitting the complex construction process into simple processes or particular operations is that it allows to speed up jobs and improve labor productivity thanks to workers' specialization focused on the performance of particular repetitive operations. Compiling teams and crews of workers having appropriate qualifications, utilization of high-performance tools and appliances, and, first of all, rational workplace management involving splitting of the spread of works into divisions and plots allow reducing labor costs and achieving a better quality of works carried out. 
The types and location of surfaces subject to stucco jobs render considerable influence on operational efficiency of teams. One of the opportunities for increasing labor productivity and efficiency during outdoor stucco operations is improving powered tools utilized to treat outer wall surfaces of buildings. The technical and economic characteristics of the process of mechanical treatment of building wall materials (stucco, brick, concrete, reinforced concrete) depend on the correct choice of tool modes and parameters. Parameters should be selected with regard to specific conditions based on physical and mechanical characteristics of wall material and tool. In the construction site setting, it is useful to get to know the following necessary physical and mechanical properties of materials to be treated: material's compression strength; composition of coarse and fine filler for concrete and reinforced concrete; presence, diameter and layout of bars when cast-in-situ structures are treated to a depth of $5-8 \mathrm{~mm}$. The laboratory tests performed have allowed selecting optimal modes of tool operation for heavy concretes and compare efficiency of different steels for the fabrication of mill stars. It is necessary to continue investigating into selection of the mode and parameters of tools for mechanical treatment of surfaces as applied to special types of concrete: polymer concretes based on silicate and carbonate fillers, concretes based on porous fillers (Tuff, Pumice, Slag, Keramzit). The Cost-efficiency of steels and alloys applied should be studied, too.

\section{Conflicts of Interest}

The authors declare no conflict of interest.

\section{References}

[1] Sinenko, S. A., B. V. Zhadanovsky, and A. Yu Slavina. "Methods of aging freshly laid concrete during the erection of monolithic structures in winter" BST Bulletin of Construction Equipment 4. (2018).

[2] Ershov M. N., Lapidus A. A., Telichenko V. I. Tekhnologicheskie protsessy v stroitel'stve (The technological processes in construction), Moscow, ASV Publ., 2016. (In Russian).

[3] Gumerova, Eliza, Olga Gamayunova, and Roman Gorshkov. "Choosing the Appropriate Way of Plastering Works for Transportation and Construction Facilities." IOP Conference Series: Earth and Environmental Science 90 (October 2017): 012185. doi:10.1088/1755-1315/90/1/012185.

[4] Vatin, Nikolay Ivanovich, and Olga Sergeevna Gamayunova. "Using Plastering Machines to Improve the Efficiency of Finishing Works." Applied Mechanics and Materials 635-637 (September 2014): $2049-2053$. doi:10.4028/www.scientific.net/amm.635-637.2049.

[5] Makovetskaya, Elena, Antonina Deniskina, Egor Krylov, and Fatima Urumova. “Organizational Optimization of Construction Processes by Virtue of Robotization." Edited by A. Zheltenkov. E3S Web of Conferences 91 (2019): 02036. doi:10.1051/e3sconf/20199102036.

[6] Bock, Thomas, Natalia Buzalo, and Alexey Bulgakov. "Mathematical Description and Optimization of Robot Control for Plastering Works.” 2018 International Multi-Conference on Industrial Engineering and Modern Technologies (FarEastCon) (October 2018). doi:10.1109/fareastcon.2018.8602717.

[7] Shreeranga B., Nishchith H., A. Kumar U.R., Ramith R., Naveen M.V., Jishnumohan D. Nair. "Design and Fabrication of Wall Plastering Machine", Journal of Mechanical Engineering and Automation, 7(5): (2017); 159-163. doi:10.5923/j.jmea.20170705.07.

[8] Ankush, N.A., Laukik, P.R. "Design of automatic wall plastering machine" International journal of engineering sciences \& research technology, (2017): 6 (3). 543-555. DOI: 10.5281/zenodo.439237.

[9] Tishkin, D. D., and K. I. Barbolin. "To the Issue of Improving the Durability of the Plaster Facades of Buildings.” Bulletin of Civil Engineers 14, no. 6 (2017): 135-139. doi:10.23968/1999-5571-2017-14-6-135-139.

[10] Pakhomova, L.A., Chernyshova, A.M. "Organizational and Technological Solutions for the Application of Leveling Finishing Coatings”, Science Prospects, 2:101, (2018): 62-71.

[11] Adams, Thomas, Anya Vollpracht, Johannes Haufe, Linda Hildebrand, and Sigrid Brell-Cokcan. "Ultra-Lightweight Foamed Concrete for an Automated Facade Application." Magazine of Concrete Research 71, no. 8 (April 2019): $424-436$. doi:10.1680/jmacr.18.00272.

[12] Gerek, Ibrahim Halil, Ercan Erdis, Gulgun Mistikoglu, and Mumtaz A. Usmen. "Evaluation of Plastering Crew Performance in Building Projects Using Data Envelopment Analysis." Technological and Economic Development of Economy 22, no. 6 (September 25, 2014): 926-940. doi:10.3846/20294913.2014.909903.

[13] Idiake, John Ebhohimen, and Mbamali Ikemefuna. "Improving Labour Performance in the Management of Wall Plastering Activity for One Storey Buildings in Abuja, Nigeria." Journal of Economics and Sustainable Development (2004). 
[14] Bokor, Orsolya, Laura Florez, Allan Osborne, and Barry J. Gledson. "Overview of Construction Simulation Approaches to Model Construction Processes.” Organization, Technology and Management in Construction: An International Journal 11, no. 1 (March 1, 2019): 1853-1861. doi:10.2478/otmcj-2018-0018.

[15] Lapidus, A.A., Tolstova, K.S., Topchy, D.V. "The Formation of Groups of Parameters Affecting the Evaluation Criteria of Permissibility of Combining Streams in the Manufacture of Building Finishing Work in Residential Buildings", Science and business: development ways, 2018, 6 (84): 18-22

[16] Zhadanovsky, Boris. "Mechanical Processing of Concrete and Reinforced Concrete with Diamond Tool." Edited by A. Mottaeva and B. Melović. MATEC Web of Conferences 193 (2018): 03013. doi:10.1051/matecconf/201819303013.

[17] Grankina, D.V., Troitskiy, V.M., Vasilieva, D.K., Matycin A.V. "Theoretical bases of processing of building structures with free abrasives", Engineering journal of Don, 1 No. 52, (2019).

[18] Oleynik, P.P., Brodsky, V.I., and Cherednichenko, N.D., "Theory, Methods, and Forms of Organization of Building Production”, part 1, publishing house Misi-Mgsu, 2019: 335.

[19] Vainshtein, M.S., Zhadanovsky, B.V., Sinenko, S.A., et al. "Evaluation of the effectiveness of organizational and technological solutions when choosing means of mechanization of construction and installation works", Scientific Review, vol 13, (2015):156-159.

[20] Opanasyuk, I.L., Opanasyuk, L.G., Reutsky, I.A., and Paytra, A.P. "Reserves for increasing the efficiency of finishing work in the construction of residential and public buildings", Bulletin of the Belarusian-Russian University, 3 No. 40, (2013): 82-91. 